\title{
Structures of the lamin A/C R335W and E347K mutants: Implications for dilated cardiolaminopathies
}

\author{
Michela Bollati ${ }^{\mathrm{a}}$, Alberto Barbiroli ${ }^{\mathrm{b}}$, Valentina Favalli ${ }^{\mathrm{c}}$, Eloisa Arbustini ${ }^{\mathrm{c}}$, Philippe Charron ${ }^{\mathrm{d}}$, \\ Martino Bolognesi ${ }^{a}, *$ \\ a Dipartimento di Scienze Biomolecolari e Biotecnologie and CIMAINA, Università degli Studi di Milano, Via Celoria 26, 20133 Milano, Italy \\ ${ }^{\mathrm{b}}$ Sezione di Biochimica, Dipartimento di Scienze Molecolari Agroalimentari, Università degli Studi di Milano, Via Celoria 2, 20133 Milano, Italy \\ ${ }^{\mathrm{C}}$ Centre for Inherited Cardiovascular Diseases, Fondazione IRCCS Policlinico San Matteo, Pavia, Italy \\ ${ }^{\mathrm{d}}$ UPMC Univ Paris 6, AP-HP, Centre de Référence des Maladies Cardiaques Héréditaires, Hôpital Pitié-Salpêtrière, Paris, France
}

\section{A R T I C L E I N F O}

\section{Article history:}

Received 22 December 2011

Available online 10 January 2012

\section{Keywords:}

Nuclear lamins

Laminopathy

Dilated cardiomyopathy

Coiled coil

Crystal structure

\begin{abstract}
A B S T R A C T
Dilated cardiomyopathy (DCM) is a condition whereby the normal muscular function of the myocardium is altered by specific or multiple aetiologies. About $25-35 \%$ of DCM patients show familial forms of the disease, with most mutations affecting genes encoding cytoskeletal proteins. Most of the DCM-related mutations fall in the Lamin AC gene, in particular in the Coil2B domain of the encoded protein. In this context, we focussed our studies on the crystal structures of two lamin Coil2B domain mutants (R335W and E347K). Both R335 and E347 are higly conserved residues whose substitution has little effects on the Coil2B domain three-dimensional structure; we can thus hypothesize that the mutations may interfere with the binding of components within the nuclear lamina, or of nuclear factors, that have been proposed to interact/associate with lamin $\mathrm{A} / \mathrm{C}$.
\end{abstract}

(c) 2012 Elsevier Inc. All rights reserved.

\section{Introduction}

The eukaryotic cell nucleus is a complex membrane-bound organelle that houses and organizes the genome, while providing/supervising its expression. In this context, the lamina, underlying the nuclear membrane, is essential for maintaining nuclear shape, spacing nuclear pore complexes, anchoring and organizing heterochromatin [1-4]. Lamina is a meshwork of nuclear-specific type $\mathrm{V}$ intermediate filaments (IF) called lamins, associated with the nuclear membrane, either directly or through interactions with membrane-bound proteins [2,3,5-8]. As a basic structural unit, lamins form coiled-coil dimers that associate longitudinally to form polar head-to-tail polymers [2,9-11]. According to their primary sequence, biochemical properties and expression patterns, lamins have been classified as A- and B-type, which are differentially expressed in cells. The Lamin AC gene (LMNA) maps on the long arm of chromosome 1 (1q21.2-q21.3) and encodes two main isoforms by alternative splicing [16], Lamin $A$ and $C$, which are ex-

Abbreviations: DCM, dilated cardiomyopathy; IF, intermediate filaments; LMNA lamin A/C; LMNAcc, lamin coil 2B domain; CD, circular dichroism; DLS, dynamic light scattering.

* Corresponding author. Fax: +3902 50314895

E-mail address: martino.bolognesi@unimi.it (M. Bolognesi). pressed exclusively in differentiated non-proliferating cells $[2,10,12,13]$.

The translated LMNA protein is a dimer (660 amino acids/ chain) hosting an elongated central $\alpha$-helical "rod" domain, flanked by non- $\alpha$-helical "head" and "tail" domains at the $\mathrm{N}$ and C-termini, respectively. Each chain contributes to the rod domain 350 amino acids that host four $\alpha$-helical segments, named $1 \mathrm{~A}, 1 \mathrm{~B}, 2 \mathrm{~A}$ and $2 \mathrm{~B}$ (in sequential order), with heptad-repeat periodicity. The four $\alpha$-helical segments are interconnected by "linkers" termed L1, L12 and L2, which are also held to adopt $\alpha$-helical conformation [14,15]. The 1A, 1B, 2A, 2B $\alpha$-helical segments build the coiled coil rod central domain in the LMNA dimer by associating with the homonymous $\alpha$-helical segments of the partner chain. In each LMNA chain, the head domain is about 30 residues and is predicted to be disordered, while the tail domain contains an evolutionary conserved 115-residue globular domain exhibiting an immunoglobulin-like fold [15-17].

Defects in the LMNA gene have been causally linked to more than 10 different diseases termed laminopathies, with occurrence of cardiac complications which, in most cases, are dilated cardiomyopathy (DCM) [18-21]. Several laminopathies affect striated muscle (Emery-Dreifuss muscular dystrophy, dilated cardiomyopathy, and limb-girdle muscular dystrophy), whereas others primarily disrupt muscle and neurons (Charcot-Marie-Tooth disorder), adipose tissue (autosomal dominant partial lipodystrophy), or adipocytes 
and bone (mandibuloacral dysplasia) [22-24]. Dilated cardiomyopathy $(\mathrm{DCM})$ is a myocardial disorder characterized by progressive ventricular dilation and impaired systolic contraction, being a major cause of congestive heart failure worldwide $[18,25]$. Here we report the crystal structures of two LMNA Coil2B domain mutants (E347K and R335W) that are discussed at the light of their implications in the context of DCM.

\section{Materials and methods}

\subsection{Cloning and mutagenesis}

The Coil2B domain (LMNAcc), comprising residues 303-397, was cloned in pEt151 directional TOPO Expression vector (Invitrogen), as a fusion construct comprising an $\mathrm{N}$-terminal hexa-Histidine affinity tag and a linker (26 residues) containing V5 epitope and TEV Protease recognition site. Mutagenesis to obtain the R335W and E347K mutants was performed on LMNAcc using Pfu-Turbo DNA polymerase (Fermentas), and two synthetic oligonucleotide primers containing the mutations. Following temperature cycling, the products were treated with Dpn I, and sequenced by BMR Sequencing Service, University of Padova, Italy.

\subsection{Expression and purification}

LMNAcc w.t. and mutants were expressed in Escherichia coli strain BL21(DE3) grown in Luria-Bertani medium (Sigma Aldrich), containing $100 \mathrm{mg} / \mathrm{ml}$ ampicillin at $37^{\circ} \mathrm{C}$ until the $\mathrm{OD}_{600}$ reached 0.8 . After cooling the cultures to $25^{\circ} \mathrm{C}$, expression of the recombinant protein was induced by the addition of $0.5 \mathrm{mM}$ isopropyl $\beta$-D-thiogalactopyranoside (IPTG) and the culture was incubated overnight. After induction, the cells were harvested by centrifugation and resuspended in $100 \mathrm{ml}$ Guanidinium Lysis Buffer (20 mM sodium phosphate pH 7.8, 6 M Guanidine $\mathrm{HCl}, 500 \mathrm{mM} \mathrm{NaCl}$ ). The cells were lyzed by sonication and then centrifuged at $23,000 \mathrm{~g}$ for $1 \mathrm{~h}$ at $4^{\circ} \mathrm{C}$. The supernatant was loaded on Nickel Sepharose Fast Flow resin (Ge-Healthcare) and eluted by gravity in $20 \mathrm{mM} \mathrm{NaH} \mathrm{PO}_{4} \mathrm{pH} 4,8 \mathrm{M}$ urea, $500 \mathrm{mM} \mathrm{NaCl}$. The fusion protein was dialyzed overnight into a refolding buffer $(20 \mathrm{mM}$ Tris- $\mathrm{HCl} \mathrm{pH} 8,150 \mathrm{mM} \mathrm{NaCl}, 2.4 \mathrm{mM}$ $\mathrm{CaCl}_{2}$ ). The buffer was subsequently changed to $10 \mathrm{mM}$ Tris- $\mathrm{HCl} \mathrm{pH} 8,500 \mathrm{mM} \mathrm{NaCl}$ using a Sephadex PD10 column. The protein was concentrated to $10 \mathrm{mg} / \mathrm{ml}$ using an Amicon Ultra centrifugal filter (Millipore).

\subsection{Circular dichroism (CD)}

Circular dichroism (CD) studies were carried out on a Jasco J810 spectropolarimeter. LMNAcc was soluted in $10 \mathrm{mM}$ Tris- $\mathrm{HCl} \mathrm{pH} 8$, $500 \mathrm{mM} \mathrm{NaCl}$ ( $8 \mathrm{M}$ urea was added for the control spectrum). Spectra of a $1 \mathrm{mg} / \mathrm{ml}$ protein solution were recorded in a $0.1 \mathrm{~cm}$ path length cell and analyzed by means of Jasco J800 software; data were normalized in terms of Mean Residual Ellipticity ([26]). Estimates of the secondary structure composition were obtained by means of CDNN version 2.1 (Copyright (c) Gerald Böhm, Institut für Biotechnologie, Martin-Luther Universität Halle-Wittenberg).

\subsection{Dynamic light scattering (DLS)}

The freshly purified proteins were centrifuged at $13,000 \mathrm{~g}$ for 10 min prior to DLS analysis; all DLS measurements were carried out at $10^{\circ} \mathrm{C}$ using a DynaPro instrument (Protein Solution, Charlottesville, USA). The DLS data on $10 \mathrm{mg} / \mathrm{ml}$ protein solutions resulted to be sufficiently monodisperse (polydispersivity is defined as the standard deviation of the hydrodynamic radius), thus suitable for crystallization experiments [27,28].

\subsection{Crystallization}

Crystallization trials on LMNAcc and mutant solutions, concentrated at $10 \mathrm{mg} / \mathrm{ml}$, were performed using an Oryx-8 crystallization robot (Douglas Instruments, East Garston, UK). After two weeks at $20^{\circ} \mathrm{C}$ no crystals grew, but vitreous spheres were observed under various growth conditions. To overcome the formation of undesired vitreous aggregation, the crystallization trials were incubated at $37^{\circ} \mathrm{C}$, at which temperature most of the spheres turned into crystals.

The largest crystals were obtained under the following conditions: 30\% 2-methyl-2,4-pentanediol, 0.1 M Hepes pH 7.5, $0.5 \mathrm{M}$ Ammonium Sulfate (LMNAcc), 15\% Ethanol, $0.1 \mathrm{M}$ Citrate pH 5.5, 0.2 M Lithium Sulfate (R335W), or 30\% 2-methyl-2,4-pentanediol, 0.1 M Sodium Acetate pH 4.6, 0.2 M Sodium Chloride (E347K).

Crystals were cryoprotected in their mother liquors, supplemented with $25 \%$ glycerol and flash-frozen in liquid nitrogen. X-ray diffraction data were collected at the European Synchrotron Radiation Facility (Grenoble, France) on beam line ID23-1. Crystals of the w.t. LMNAcc and R335W mutant diffracted both to $3.0 \AA$, while crystals of the E347K mutant diffracted to $3.6 \AA$. All crystals are isomorphous and were shown to belong to the hexagonal space group $\mathrm{P}_{5} 22$. The diffraction data were processed using the program iMOSFLM [29] and intensities merged using Scala [30]; data reduction statistics are reported in Table 1. The crystal structures were solved by molecular replacement using the program MOLREP [31]. The LMNAcc structure (PDB code: 1X8Y [11]) was used as search model. A single protein molecule was located in the crystal asymmetric unit (statistics for the molecular replacement solutions are listed in Table 1). The positioned model molecule was subjected to rigid-body refinement and refined using REFMAC5 [32]. A random set comprising $5 \%$ of the data was omitted from refinement for $R_{\text {free }}$ calculation. The amino acid sequence of the model was modified to match the mutants correct sequence and fitted to the electron density using the program Coot [33]. A set of final refinement cycles was performed using the program Buster [34] until the $R_{\text {factor }}$ and $R_{\text {free }}$ values reached the values listed in Table 1 . The stereochemical quality of the model was checked using the program PROCHECK [35]. Atomic coordinates and structure factors for LMNAcc, R335W and E347K mutants have been deposited with the PDB [36], with accession codes 3V5B, 3V4Q and $3 \mathrm{~V} 4 \mathrm{~W}$, respectively.

\subsection{Genetic studies}

The 12 exons of the LMNA gene were amplified from peripheral blood-derived genomic DNA by means of polymerase chain reaction (PCR), using primers derived from intronic sequences [37]. The PCR products were analyzed by means of denaturing high-performance liquid chromatography (Transgenomic, San Jose, CA) using the Wave DNA Fragment Analysis System. Heteroduplex fragments were purified (QIAquick Kit, Qiagen, Santa Clarita, CA) and then sequenced using a BigDye-terminator cycle sequencing system (ABI PRISM, Applied Biosystem, Foster City, CA). LMNA gene analysis was performed by direct bidirectional automated sequencing in case of probands with healthy parents, to exclude the rare possibility of recessive forms. The control series for each mutation is composed of 800 normal individuals. Reference sequences used in the study are: LMNA gene: GenBank ID: NC_000001; LMNA mRNA: GenBank ID: NM_170707; Lamin A protein: GenBank ID: NP_733821; LMNC mRNA: GenBank ID: NM 005572; Lamin C protein: GenBank ID: NP005563. 
Table 1

$\mathrm{X}$-ray data collection and refinement statistics.

\begin{tabular}{|c|c|c|c|}
\hline & LMNAcc & R335W & E347K \\
\hline \multicolumn{4}{|l|}{ Data collection statistics } \\
\hline Space group & $\mathrm{P}_{5} 22$ & $\mathrm{P}_{5} 22$ & $\mathrm{P}_{5} 22$ \\
\hline Unit-cell parameters $\left(\AA{ }^{\circ}{ }^{\circ}\right)$ & $\begin{array}{l}a=b=90.2 \quad c=74.7 \\
\alpha=\beta=90 \quad \gamma=120\end{array}$ & $\begin{array}{l}a=b=90.5 \quad c=75.4 \\
\alpha=\beta=90 \quad \gamma=120\end{array}$ & $\begin{array}{l}a=b=90.2 \quad c=74.9 \\
\alpha=\beta=90 \quad \gamma=120\end{array}$ \\
\hline Resolution limits $(\AA)$ & $74.7-3.0(3.2-3.0)$ & $75.4-3.1(3.2-3.1)$ & $78.2-3.7(3.8-3.7)$ \\
\hline No of unique reflections & $3889(524)$ & $3760(525)$ & $2316(314)$ \\
\hline Completeness (\%) & $100(100)$ & $99.7(100)$ & $99.1(95.6)$ \\
\hline Redundancy & $9.3(7.9)$ & $9.8(10.5)$ & $11.6(9.3)$ \\
\hline$R_{\text {merge }}(\%)^{\mathrm{a}}$ & $5.8(57)$ & $6.7(51.7)$ & $11.6(24.2)$ \\
\hline Average $I / \sigma(I)$ & $28.6(3.4)$ & $23.5(4.5)$ & $19.1(10.6)$ \\
\hline \multicolumn{4}{|l|}{ Refinement statistics } \\
\hline$R_{\text {factor }}(\%)^{\mathrm{b}}$ & 28.0 & 28.2 & 33.8 \\
\hline$R$-free $(\%)^{\mathrm{c}}$ & 33.0 & 30.5 & 34.4 \\
\hline Average $\mathrm{B}\left(\AA^{2}\right)$ & 101.4 & 84.0 & 96.3 \\
\hline R.M.S. bond lengths $(\AA)$ & 0.009 & 0.009 & 0.010 \\
\hline R.M.S. bond angles $\left({ }^{\circ}\right)$ & 1.13 & 1.03 & 1.17 \\
\hline \multicolumn{4}{|l|}{ Ramachandran plot } \\
\hline Resid. in most fav. reg. (\%) & 88.7 & 98.6 & 93.0 \\
\hline Resid. in add. allow. reg. (\%) & 11.3 & 1.4 & 7.0 \\
\hline Resid. in disallow. reg. (\%) & 0.0 & 0.0 & 0.0 \\
\hline PDB code & $3 V 5 B$ & $3 V 4 Q$ & $3 \mathrm{~V} 4 \mathrm{~W}$ \\
\hline
\end{tabular}

High resolution shell values in brackets.

a $R_{\text {merge }}=\sum|I-(I)| / \sum I \times 100$, where $I$ is intensity of a reflection and $(I)$ is the average intensity.

${ }^{\mathrm{b}} R_{\text {factor }}=\sum \mid F_{\mathrm{o}}-F_{\mathrm{c}} / \sum F_{\mathrm{o}} \times 100$.

c $R_{\text {free }}$ is calculated from $5 \%$ randomly selected data for crossvalidation.

\section{Results and discussion}

\subsection{Production and physical characterization of the proteins}

We have cloned three recombinant fragments of human LMNA which represent the main part of the Coil2B segment (residues 305-397, LMNAcc); these are the wild type LMNAcc, and the two mutants R335W and E347K. The proteins were produced by refolding from denatured inclusion bodies; thus, the proteins were characterized by biophysical analyses in order to verify their correct fold after purification. We performed a circular dichroism (CD) analysis on the LMNAcc sample. The CD spectra highlighted a correctly folded protein composed of $87 \% \alpha$-helical secondary structure, consistent with the LMNAcc structure, which consists of an extended $\alpha$-helix (Fig. 1). The remaining $13 \%$ of non $\alpha$-helical structure recorded by the CD spectra is likely due to the His-Tag residues ( 6 residues) and to the linker between His-Tag and LMNAcc added in the cloning procedure (26 residues). In order to

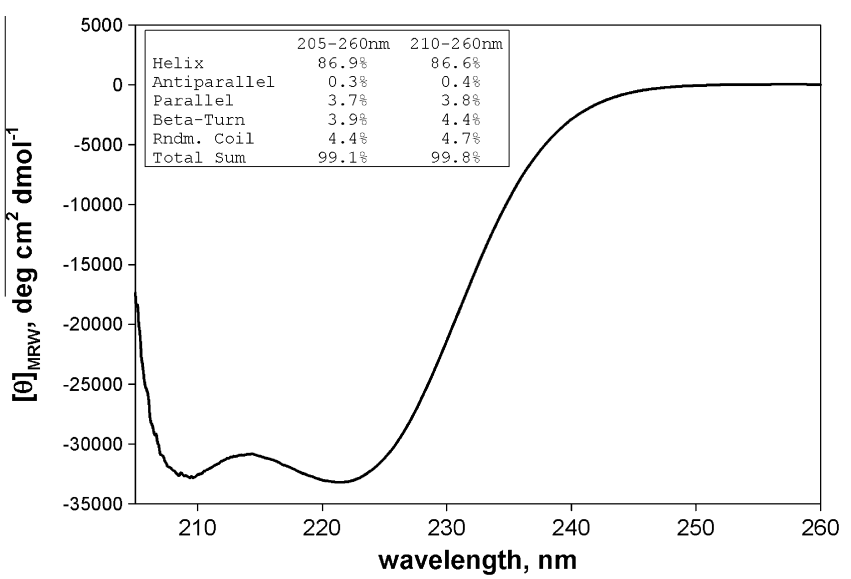

Fig. 1. LMNAcc circular dichroism studies. Main figure: far-UV CD spectra; inset: estimation of $\alpha$-helical content by CDNN software version 2.1 . study the stability of the protein, DLS measurements were carried out at different LMNAcc concentrations. The results showed that at $10 \mathrm{mg} / \mathrm{ml}$ LMNAcc proved sufficiently monodisperse (19\%) to justify crystallization experiments. The results obtained on LMNAcc were used as a guideline for preparation of mutant samples.

\subsection{Overall structure}

We could grow crystals of w.t. LMNAcc and the mutant domains in the hexagonal space group $\mathrm{P}_{5} 22$, with one molecule per asymmetric unit. The protein structure was solved using molecular replacement techniques and refined to 3.0 and $3.6 \AA$ resolution (for LMNAcc/R335W, and for E347K, respectively). The final crystallographic $R_{\text {factor }}$ for LMNAcc is $28 \%$ and $R_{\text {free }}$ is $33 \%$; for R335W $R_{\text {factor }}$ is $27.4 \%$ and $R_{\text {free }}$ is $28.6 \%$; the E347K structure was refined to an $R_{\text {factor }}$ value of $32 \%$ and $R_{\text {free }} 34.7 \%$ (see Table 1 ). Both w.t. and mutant models comprise amino acids 313-386 (sequence numbers refer to full length LMNA). Superimposition of LMNAcc and its mutants showed that the overall conformation of the molecules is strongly conserved, as expected considering the single residue mutations and crystal isomorphism. Nevertheless, all the three protein structures appear progressively disordered towards the $\mathrm{N}$-terminus. In particular, the first eight $\mathrm{N}$-terminal residues (305-312) and the thirty-six tail residues added in the cloning procedure could not be modelled (while revealing some residual weak electron density). Residues 313-315 exhibit only poor density, which was however sufficient to trace the helix path unambiguously; the rest of the structure exhibits fairly good electron density. The final models display excellent overall stereochemical parameters as reported in Table 1 . The overall structure of the crystallized LMNAcc consists essentially of a single long $\alpha$-helix (Fig. 2A). However, around residues 345-355 LMNAcc displays a discontinuity of the heptad-repeat, the so-called "stutter", that is an insertion of four extra residues occurring roughly at the center of segment $2 \mathrm{~B}$ in all IF proteins [38]. The crystallographic analyses revealed that w.t. and mutant LMNAcc display one polypeptide chain per asymmetric unit. However, LMNAcc builds up a parallel coiled coil dimer, as reported for the full length protein, through assembly 
with a symmetry equivalent molecule in the crystal lattice (Fig. 2B). The dimer is positioned on a crystallographic 2 -fold axis, and exhibits a number of intermolecular salt bridges, which stabilize association of the two chains in two main regions at the termini of the domain (residues 313-321 and 369-376). In addition to the canonical coiled coil hydrophobic packing, two main salt bridges are found that probably contribute to the specificity of this interaction. The first occurs between residue Glu342 and the side chain of Lys341 from the opposed chain in the coil. The second salt bridge links Arg331 and Glu330, again of the opposed LMNAcc chain.

\subsection{Structure of DCM-related mutations in Coil2B domain}

Most of the more than 100 mutations related to human DCM fall in the lamin A rod domain $[18,25,37]$. The side chains of
Arg335 and Glu347, mutated in this work, are shown by the crystal structures to be exposed at the surface of the coiled coil dimer (Fig. 3); nevertheless, the mutations occur at sites that are highly conserved in the known LMNA amino acid sequences $[11,39]$. Within the vertebrate IF superfamily, Arg335 is a highly conserved residue, stressing its key role in the correctly folded coil/rod. A mutation to Trp may hamper stability of the coiled-coil, either because of steric hindrance or charge modification. A destabilization of the quaternary assembly, or the achievement of a looser coil, may be at the roots of the pathogenic effect of the R335W mutation, although the substitution of Arg335 with Trp does not perturb the overall conformation of the helix. The second mutated residue, Glu347, is highly conserved through the phyla, except for the invertebrate lamins. The substitution with a positively charged residue, as Lys, might interfere with the formation of an intra- or inter-helical salt bridge, or other forms of polar interaction. Both

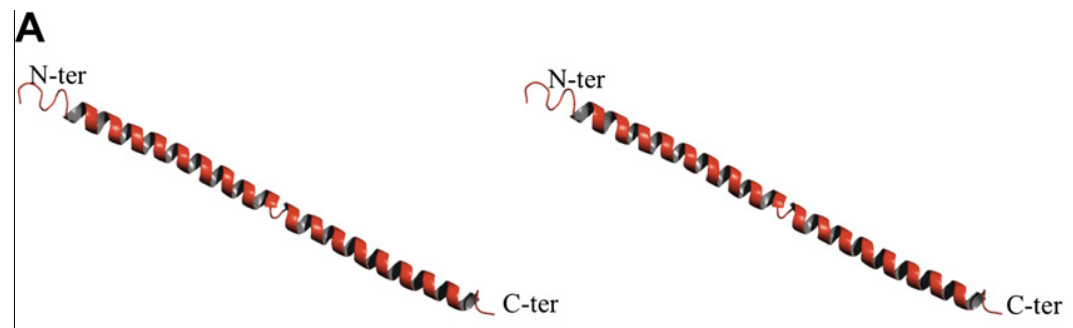

B

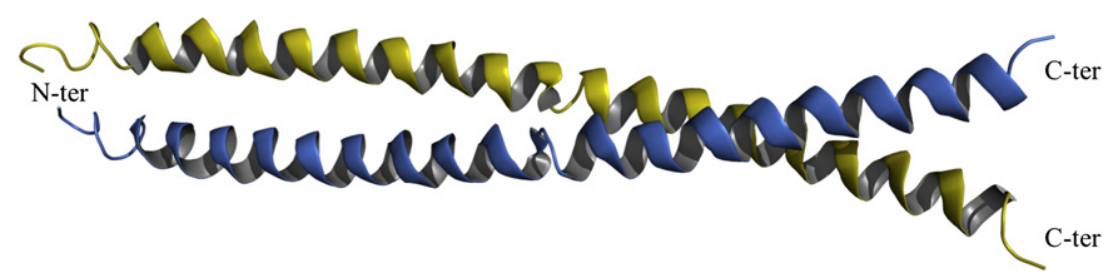

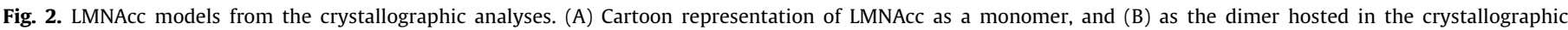
asymmetric unit. The stutter region, breaking the $\alpha$-helical continuity, is defined by a thin line and labelled.

A

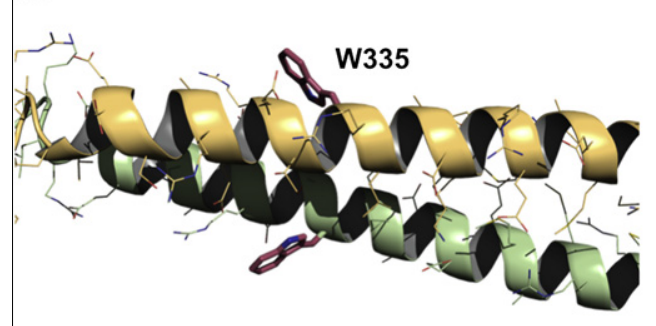

B

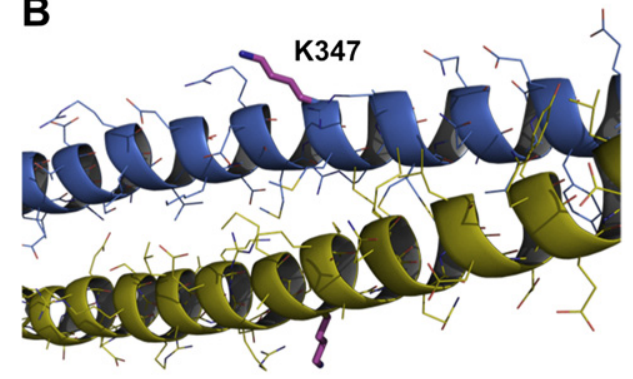

\section{C}

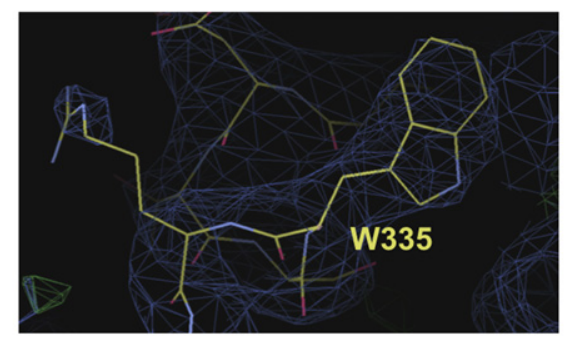

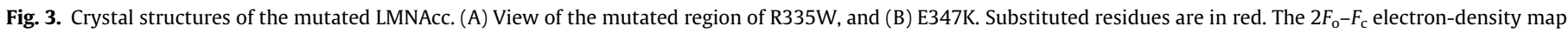

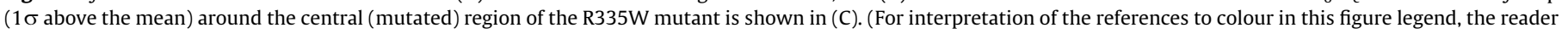
is referred to the web version of this article.) 
mutations may alter the interactions of the coiled-coil dimer, and consequently interfere with the lamina assembly; alternatively, they may affect the binding of components within the nuclear lamina, including nuclear factors, that have been proposed to interact/ associate with LMNA [40-43].

\section{Acknowledgments}

This work was supported by the European Union FP7 Collaborative Research Project IINHERITANCE (Project No. 291924). We are grateful to collaborators within the INHERITANCE Project, and to Dr. Cecilia Trovati (Pavia) for continuous assistance.

\section{References}

[1] S.P. Lees-Miller, Dysfunction of lamin A triggers a DNA damage response and cellular senescence, DNA Repair (Amst) 5 (2006) 286-289.

[2] B. Burke, C.L. Stewart, Life at the edge: the nuclear envelope and human disease, Nat. Rev. Mol. Cell Biol. 3 (2002) 575-585.

[3] Y. Gruenbaum, A. Margalit, R.D. Goldman, D.K. Shumaker, K.L. Wilson, The nuclear lamina comes of age, Nat. Rev. Mol. Cell Biol. 6 (2005) 21-31.

[4] H.J. Worman, J.C. Courvalin, Nuclear envelope, nuclear lamina, and inherited disease, Int. Rev. Cytol. 246 (2005) 231-279.

[5] R.D. Goldman, Y. Gruenbaum, R.D. Moir, D.K. Shumaker, T.P. Spann, Nuclear lamins: building blocks of nuclear architecture, Genes Dev. 16 (2002) 533-547.

[6] S. Vlcek, R. Foisner, A-type lamin networks in light of laminopathic diseases, Biochim. Biophys. Acta 1773 (2007) 661-674.

[7] C.J. Hutchison, Lamins: building blocks or regulators of gene expression? Nat. Rev. Mol. Cell Biol. 3 (2002) 848-858.

[8] M.S. Zastrow, S. Vlcek, K.L. Wilson, Proteins that bind A-type lamins: integrating isolated clues, J. Cell Sci. 117 (2004) 979-987.

[9] C.J. Hutchison, H.J. Worman, A-type lamins: guardians of the soma? Nat. Cell Biol. 6 (2004) 1062-1067.

[10] L.C. Mounkes, B. Burke, C.L. Stewart, The A-type lamins: nuclear structura proteins as a focus for muscular dystrophy and cardiovascular diseases, Trends Cardiovasc. Med. 11 (2001) 280-285.

[11] S.V. Strelkov, J. Schumacher, P. Burkhard, U. Aebi, H. Herrmann, Crysta structure of the human lamin A coil 2B dimer: implications for the head-to-tail association of nuclear lamins, J. Mol. Biol. 343 (2004) 1067-1080.

[12] F. Lin, H.J. Worman, Structural organization of the human gene encoding nuclear lamin A and nuclear lamin C, J. Biol. Chem. 268 (1993) 16321-16326.

[13] D.Z. Fisher, N. Chaudhary, G. Blobel, CDNA sequencing of nuclear lamins A and $C$ reveals primary and secondary structural homology to intermediate filament proteins, Proc. Natl. Acad. Sci. USA 83 (1986) 6450-6454.

[14] D.A. Parry, P.M. Steinert, Intermediate filament structure, Curr. Opin. Cell Biol. 4 (1992) 94-98.

[15] S.V. Strelkov, H. Herrmann, U. Aebi, Molecular architecture of intermediate filaments, Bioessays 25 (2003) 243-251.

[16] S. Dhe-Paganon, E.D. Werner, Y.I. Chi, S.E. Shoelson, Structure of the globular tail of nuclear lamin, J. Biol. Chem. 277 (2002) 17381-17384.

[17] I. Krimm, C. Ostlund, B. Gilquin, J. Couprie, P. Hossenlopp, J.P. Mornon, G. Bonne, J.C. Courvalin, H.J. Worman, S. Zinn-Justin, The Ig-like structure of the C-terminal domain of lamin A/C, mutated in muscular dystrophies, cardiomyopathy, and partial lipodystrophy, Structure 10 (2002) 811-823.

[18] D. Fatkin, C. MacRae, T. Sasaki, M.R. Wolff, M. Porcu, M. Frenneaux, J. Atherton, H.J. Vidaillet Jr., S. Spudich, U. De Girolami, J.G. Seidman, C. Seidman, F. Muntoni, G. Muehle, W. Johnson, B. McDonough, Missense mutations in the rod domain of the lamin $\mathrm{A} / \mathrm{C}$ gene as causes of dilated cardiomyopathy and conduction-system disease, N. Engl. J. Med. 341 (1999) 1715-1724.

[19] S. Bione, E. Maestrini, S. Rivella, M. Mancini, S. Regis, G. Romeo, D. Toniolo, Identification of a novel X-linked gene responsible for Emery-Dreifuss muscular dystrophy, Nat. Genet. 8 (1994) 323-327.

[20] G. Bonne, M.R. Di Barletta, S. Varnous, H.M. Becane, E.H. Hammouda, L. Merlini, F. Muntoni, C.R. Greenberg, F. Gary, J.A. Urtizberea, D. Duboc, M. Fardeau, D. Toniolo, K. Schwartz, Mutations in the gene encoding lamin $\mathrm{A} / \mathrm{C}$ cause autosomal dominant Emery-Dreifuss muscular dystrophy, Nat. Genet. 21 (1999) 285-288.

[21] S. Shackleton, D.J. Lloyd, S.N. Jackson, R. Evans, M.F. Niermeijer, B.M. Singh, H. Schmidt, G. Brabant, S. Kumar, P.N. Durrington, S. Gregory, S. O'Rahilly, R.C. Trembath, LMNA, encoding lamin A/C, is mutated in partial lipodystrophy, Nat. Genet. 24 (2000) 153-156.

[22] L. Mounkes, S. Kozlov, B. Burke, C.L. Stewart, The laminopathies: nuclear structure meets disease, Curr. Opin. Genet. Dev. 13 (2003) 223-230.

[23] C.L. Navarro, A. De Sandre-Giovannoli, R. Bernard, I. Boccaccio, A. Boyer, D. Genevieve, S. Hadj-Rabia, C. Gaudy-Marqueste, H.S. Smitt, P. Vabres, L. Faivre, A. Verloes, T. Van Essen, E. Flori, R. Hennekam, F.A. Beemer, N. Laurent, M. Le Merrer, P. Cau, N. Levy, Lamin A and ZMPSTE24 (FACE-1) defects cause nuclear disorganization and identify restrictive dermopathy as a lethal neonatal laminopathy, Hum. Mol. Genet. 13 (2004) 2493-2503.

[24] H. Van Esch, A.K. Agarwal, P. Debeer, J.P. Fryns, A. Garg, A homozygous mutation in the lamin $A / C$ gene associated with a novel syndrome of arthropathy, tendinous calcinosis, and progeroid features, J. Clin. Endocrinol. Metab. 91 (2006) 517-521.

[25] P.M. Jakobs, E.L. Hanson, K.A. Crispell, W. Toy, H. Keegan, K. Schilling, T.B. Icenogle, M. Litt, R.E. Hershberger, Novel lamin A/C mutations in two families with dilated cardiomyopathy and conduction system disease, J. Card. Fail. 7 (2001) 249-256.

[26] S.M. Kelly, T.J. Jess, N.C. Price, How to study proteins by circular dichroism, Biochim. Biophys. Acta 1751 (2005) 119-139.

[27] A.R. Ferre-D'Amare, S.K. Burley, Use of dynamic light scattering to assess crystallizability of macromolecules and macromolecular assemblies, Structure 2 (1994) 357-359.

[28] A. Zulauf, M. D'Arcy, Light scattering of proteins as a criterion for crystallization, J. Crystal Growth 122 (1992) 5.

[29] I. Steller, R. Bolotovsky, M.G. Rossmann, An algorithm for automatic indexing of oscillation images using Fourier analysis, J. Appl. Crystallogr. 30 (1997) 5.

[30] n. Collaborative Computational Project, The CCP4 suite: programs for protein crystallography, Acta Crystallogr. D Biol. Crystallogr. 50 (1994) 760-763.

[31] A. Vagin, A. Teplyakov, MOLREP: an automated program for molecular replacement, J. Appl. Crystallogr. 30 (1997) 4.

[32] M.D. Winn, M.N. Isupov, G.N. Murshudov, Use of TLS parameters to model anisotropic displacements in macromolecular refinement, Acta Crystallogr. D. Biol. Crystallogr. 57 (2001) 122-133.

[33] P. Emsley, K. Cowtan, Coot: model-building tools for molecular graphics, Acta Crystallogr. D. Biol. Crystallogr. 60 (2004) 2126-2132.

[34] E. Blanc, P. Roversi, C. Vonrhein, C. Flensburg, S.M. Lea, G. Bricogne, Refinement of severely incomplete structures with maximum likelihood in BUSTER-TNT, Acta Crystallogr. D. Biol. Crystallogr. 60 (2004) 2210-2221.

[35] R.A. Laskowski, M.W. Macarthur, D.S. Moss, J.M. Thornton, PROCHECK: a program to check the stereochemical quality of protein structures, J. Appl. Crystallogr. 26 (1993) 9.

[36] H.M. Berman, J. Westbrook, Z. Feng G. Gilliland, T.N. Bhat, H. Weissig, I.N. Shindyalov, P.E. Bourne, The protein data bank, Nucleic Acids Res. 28 (2000) 235-242.

[37] E. Arbustini, A. Pilotto, A. Repetto, M. Grasso, A. Negri, M. Diegoli, C. Campana, L. Scelsi, E. Baldini, A. Gavazzi, L. Tavazzi, Autosomal dominant dilated cardiomyopathy with atrioventricular block: a lamin A/C defect-related disease, J. Am. Coll. Cardiol. 39 (2002) 981-990.

[38] K. Weber, N. Geisler, Intermediate filaments: structural conservation and divergence, Ann. NY Acad. Sci. 455 (1985) 126-143.

[39] S.V. Strelkov, H. Herrmann, N. Geisler, T. Wedig, R. Zimbelmann, U. Aebi, P. Burkhard, Conserved segments $1 \mathrm{~A}$ and $2 \mathrm{~B}$ of the intermediate filament dimer: their atomic structures and role in filament assembly, EMBO J. 21 (2002) 1255-1266.

[40] N. Kubben, J.W. Voncken, J. Demmers, C. Calis, G. van Almen, Y. Pinto, T. Misteli, Identification of differential protein interactors of lamin A and progerin, Nucleus 1 (2010) 513-525.

[41] E.C. Schirmer, R. Foisner, Proteins that associate with lamins: many faces, many functions, Exp. Cell Res. 313 (2007) 2167-2179.

[42] K.L. Wilson, R. Foisner, Lamin-binding Proteins, Cold Spring Harb Perspect, Biol. 2 (2010) a000554

[43] D. Dorner, J. Gotzmann, R. Foisner, Nucleoplasmic lamins and their interaction partners, LAP2alpha, Rb, and BAF, in transcriptional regulation, FEBS J. 274 (2007) 1362-1373. 